\title{
Produtividade e composição físico-química de bagas de cultivares de uva em distintos porta-enxertos
}

\author{
Renata Vieira da Mota(1), Claudia Rita de Souza(2), Ana Carolina Favero(3), Camila Pinheiro Carvalho e Silva(1), \\ Ezequiel Lopes do Carmo(1), Anderson Ridolfi Fonseca ${ }^{(1)}$ e Murillo de Albuquerque Regina ${ }^{(1)}$
}

\begin{abstract}
(1)Núcleo Tecnológico EPAMIG Uva e Vinho, Caixa Postal 33, CEP 37780-000 Caldas, MG. E-mail: renata@epamigcaldas.gov.br, murillo@epamigcaldas.gov.br, k_mila_pinheiro@hotmail.com, pacaraima@bol.com.br, link@epamigcaldas.gov.br ${ }^{(2)}$ Instituto Agronômico do Paraná, Área de Ecofisiologia, Caixa Postal 481, CEP 86047-902 Londrina, PR. E-mail: crsouza@iapar.br (3)Universidade Federal de Lavras, Departamento de Agricultura, Caixa Postal 3037, CEP 37200-000 Lavras, MG. E-mail: acfavero@yahoo.com.br
\end{abstract}

Resumo-O objetivo deste trabalho foi avaliar a influência de nove porta-enxertos na produção e composição química das bagas de uvas de mesa e de processamento durante o período de 2006 a 2008 em Caldas, MG. As cultivares Niágara Rosada e Folha de Figo foram enxertadas sobre 'IAC 572', 'IAC 313', 'IAC 766', '420 A', '1103 Paulsen', 'Traviú', '196-17', 'Gravesac' e 'RR 101-14' e submetidas ao delineamento em blocos ao acaso com dez tratamentos (nove porta-enxertos e o pé-franco) e quatro repetições. Ambas cultivares apresentaram maior produção sobre 'IAC 572', porém com prejuízo para a qualidade das bagas que apresentaram menor relação sólidos solúveis/acidez, menor teor de antocianinas e de compostos fenólicos e maior acidez. A absorção de potássio foi mais dependente do porta-enxerto em 'Niágara Rosada'; a maior absorção foi com os porta-enxertos 'IAC 766' e 'Traviú'. Videiras enxertadas sobre '196-17' apresentaram o menor teor de potássio nas bagas. 'Niágara Rosada' apresentou produção de $9 \mathrm{~kg}$ por planta e elevada relação sólidos solúveis/acidez sobre 'RR 101-14', '420 A' e 'Gravesac'. Entretanto, 'Gravesac' proporcionou maior concentração de antocianinas. 'Folha de Figo' enxertada em '196-17' apresentou elevado teor de sólidos solúveis, antocianinas e fenólicos nas cascas e menor teor de acidez e fenólicos nas sementes, além de produção de $5 \mathrm{~kg}$ por planta, estatisticamente semelhante aos porta-enxertos mais produtivos.

Termos para indexação: Vitis labrusca, antocianinas, manejo, produção, qualidade.

\section{Productivity and physicochemical composition of berries of grapevine cultivars grafted onto different rootstocks}

\begin{abstract}
This work aimed at evaluating the influence of nine rootstocks on the productivity and chemical composition of table and processing grapes from 2006 to 2008 in Caldas, MG. The cultivars Niagara Rosada and Folha de Figo were grafted onto 'IAC 572', 'IAC 313', 'IAC 766', '420 A', '1103 Paulsen', 'Traviú', '196-17', 'Gravesac' and 'RR 101-14' and submitted to a randomized block design with ten treatments (nine rootstocks and ungrafted plant) with four replicates. Both cultivars had higher yields when grafted onto 'IAC 572', however with impairment to berry quality, showed by lower soluble solids/acidity ratio, anthocyanins and phenolic compounds and higher total acidity. The effect of rootstock on potassium uptake was more pronounced in 'Niagara Rosada' than in 'Folha de Figo', whereby 'IAC 766' and 'Traviư' were responsible for the highest potassium uptake. Vines grafted onto '196-17' showed lower potassium levels on berries. 'Niagara Rosada' yielded $9 \mathrm{~kg}$ per plant and showed high soluble solids/acidity ratio when grafted onto 'RR 101-14', '420 A' and 'Gravesac'. 'Gravesac', however, provided the higher anthocyanin content. 'Folha de Figo' grafted onto '196-17' showed high soluble solids, anthocyanins and skin phenolic compounds contents and low acidity and seeds phenolic compounds, with a yield of $5 \mathrm{~kg}$ per plant, behaving statistically similarly to the most productive rootstocks.
\end{abstract}

Index terms: Vitis labrusca, anthocyanins, management, yield, quality.

\section{Introdução}

A região vitícola do Sul de Minas Gerais, composta principalmente pelos municípios de Caldas, Andradas e Santa Rita de Caldas, é tradicional no cultivo de uvas de origem americana (Vitis labrusca e Vitis bourquina), com área de produção estabilizada em torno de 350 ha. As principais cultivares utilizadas são Folha de Figo (Bordô),
Jacquez, Niágara Rosada e Niágara Branca. O principal destino da produção de uvas da região é o processamento para elaboração de vinhos e sucos e, no caso da 'Niágara Rosada', para consumo in natura. O perfil do viticultor da regiãoe de agricultura familiar e tradicional, com parreirais conduzidos em espaldeira, grande parte implantada em pé-franco (Protas et al., 2006). 
A baixa produtividade dos parreirais, entretanto, causou um declínio na viticultura da região, que resultou em redução da área plantada e fechamento da maioria das vinícolas. A baixa produtividade é consequência, em grande parte, da presença da filoxera (Daktulosphaira vitifoliae), afídeo que danifica as raízes da videira, das condições adversas do solo, em especial da elevada acidez, e da adoção de sistemas de condução inadequados (Regina et al., 1998).

$\mathrm{O}$ porta-enxerto influencia o crescimento vegetativo, a produção e a qualidade do cacho da videira, porém as respostas variam conforme as condições edafoclimáticas e a cultivar-copa sobre ela enxertada. Em Taubaté, SP, a produção, o vigor e a qualidade dos cachos da videira 'Niágara Rosada' foram avaliados em cinco porta-enxertos. Os porta-enxertos 'IAC 313', 'IAC 766' e 'Traviú' proporcionaram maior produtividade e tamanho de bagas, enquanto 'Kober 5BB' e 'Schwarzmann' promoveram maior teor de sólidos solúveis (Pauletto et al., 2001a, 2001b). Em Monte Alegre do Sul, SP, foi avaliada a produtividade da cultivar Niágara Rosada nos porta-enxertos 'Schwarzmann', 'IAC 572', 'IAC 313', 'Traviú', 'IAC 766' e 'Kober 5BB'. As plantas conduzidas no porta-enxerto 'Kober 5BB' apresentaram a menor produtividade em comparação com as demais variedades testadas, resultado de menor número de cachos por planta e menor peso médio dos cachos (Terra et al., 2003).

De maneira geral, a indicação de porta-enxertos baseia-se na melhor adaptação deles às condições ambientais e à compatibilidade com a copa, o que afeta diretamente a produtividade e algumas características químicas da baga, como $\mathrm{pH}$, acidez e teor de sólidos solúveis ( ${ }^{\circ}$ Brix). Entretanto, a absorção de nutrientes, o acúmulo de compostos fenólicos e o teor de antocianinas são parâmetros de qualidade que também devem ser levados em conta na escolha da melhor combinação copa/porta-enxerto.

As características físicas e o acúmulo de nutrientes nos cachos da cultivar Niágara Rosada sobre os porta-enxertos 'Ripária do Traviú' e 'IAC 766' foram avaliados em cultivos na região de Jundiaí, SP (Tecchio et al., 2007). Os autores observaram resultados semelhantes na produtividade e nas características físicas dos cachos, entretanto houve diferenças no teor de nutrientes nas folhas e no acúmulo de nutrientes pelos cachos. Uvas apirenas da cultivar Ruby Seedless apresentaram coloração menos intensa quando enxertadas sobre '110 Richter', 'du Lot', '140 Ruggeri' e '41B' (Ezzahouaini \& Williams, 1995).

A maturação ideal das uvas destinadas ao consumo in natura é estabelecida principalmente pela determinação do teor de sólidos solúveis totais (mínimo de 16\%) e pela relação sólidos solúveis/ acidez, determinante na palatabilidade e intensidade de cor (Gil \& Pszczólkowski, 2007). Para as uvas destinadas ao processamento, o critério mais utilizado é o teor de açúcares e acidez total (Guerra, 2002). Entretanto, quando o objetivo é elaborar vinhos de qualidade, a relação açúcar/acidez total não é suficiente para garantir que a uva seja colhida em seu potencial máximo de maturação. Desta forma, outros critérios devem ser considerados, como peso das bagas, potássio, $\mathrm{pH}$, compostos fenólicos, antocianinas e precursores de aromas (Augustin \& Glories, 1992; Guerra, 2002; Gil \& Pszczólkowski, 2007).

A composição química das bagas é influenciada pelo estágio de maturação, potencial genético, clima e manejo. O aumento da intensidade luminosa, sanidade dos cachos e fertilidade moderada da planta contribuem para um aumento na formação de compostos secundários, incluindo os fenólicos (Conde et al., 2007).

Dos elementos minerais presentes na baga madura, o potássio é considerado o mais importante, não apenas pela sua quantidade, que pode representar até $50 \%$ do total de minerais presentes na baga, mas também pela sua importância como ativador de enzimas, no transporte de açúcares e outros minerais e no controle do potencial osmótico (Conde et al., 2007). É também o elemento mineral que neutraliza os ácidos livres presentes na baga durante a maturação e contribui para o aumento do $\mathrm{pH}$ e redução da acidez total (Rizzon \& Sganzerla, 2007).

Ao considerar os fatores que interferem na composição das bagas, é importante a escolha da melhor combinação copa/porta-enxerto para associar o controle do vigor da planta e a qualidade das bagas com uma produtividade economicamente viável.

Este trabalho teve como objetivo avaliar a influência de diferentes porta-enxertos na produção e composição química de bagas de uvas de mesa e de processamento no período de 2006 a 2008 em Caldas, MG. 


\section{Material e Métodos}

Foram avaliadas bagas das cultivares Niágara Rosada e Folha de Figo (Bordô) em vinhedo experimental localizado em Caldas, $\mathrm{MG}\left(21^{\circ} \mathrm{S}\right.$ e $40^{\circ} \mathrm{W}$, a $1.150 \mathrm{~m}$ de altitude), com temperatura média de $18^{\circ} \mathrm{C}$, umidade relativa de $77 \%$ e precipitação pluviométrica de $1.600 \mathrm{~mm}$ anuais. As plantas, enxertadas no campo em 1998, foram conduzidas em sistema de espaldeira com três fios de arame em duplo cordão esporonado, com espaçamento de 2,5x1,5 m e densidade de 2.666 plantas ha $^{-1}$. Foi utilizado o sistema de poda curta, realizada em agosto, que manteve duas gemas por esporão em um total de 20 gemas por planta. A colheita foi realizada em janeiro.

A adubação foi feita conforme a recomendação para essa cultura no Estado de Minas Gerais: foram utilizados $60 \mathrm{~g}$ de $\mathrm{P}_{2} \mathrm{O}_{5}$ por planta, aplicados no inverno, nas entrelinhas de plantio, e $40 \mathrm{~g}$ de $\mathrm{N}$ e $120 \mathrm{~g}$ de $\mathrm{K}_{2} \mathrm{O}$ por planta, em cobertura (Ribeiro et al., 1999).

O trabalho foi constituído de dois experimentos, um para cada uma das cultivares-copa. Para cada experimento foi utilizado o delineamento em blocos ao acaso, com dez tratamentos representados por nove porta-enxertos ('IAC 572', 'IAC 313', 'IAC 766', '420 A', '1103 Paulsen', 'Traviú', '196-17', 'Gravesac' e 'RR 101-14'), e o pé-franco da variedade produtora, com quatro repetições e quatro plantas úteis por parcela. As avaliações foram realizadas em janeiro de 2006, 2007 e 2008, que representam os anos agrícolas de 2005/2006, 2006/2007 e 2007/2008.

A produção foi estimada pela massa média dos cachos obtida na colheita e pela contagem do número de cachos por planta. $O$ vigor, pela pesagem do material retirado pela poda de inverno em balança Filizola, modelo 34.

$\mathrm{Na}$ análise da composição química das bagas, foram avaliados o teor de sólidos solúveis, $\mathrm{pH}$ e acidez total titulável no mosto, antocianinas e fenólicos totais nas cascas, fenólicos totais nas sementes e teor de potássio nas bagas.

Na colheita, 200 bagas foram coletadas de forma aleatória para cada repetição e esmagadas manualmente. $\mathrm{O}$ mosto foi analisado quanto ao $\mathrm{pH}$ em medidor de $\mathrm{pH}$ Micronal modelo B474 calibrado com padrões 4,0 e 7,0 , quanto ao teor de sólidos solúveis totais ( ${ }^{\circ}$ Brix) em refratômetro digital portátil Atago modelo Pal-1, e quanto à acidez total por titulação com $\mathrm{NaOH} 0,1 \mathrm{~N}$ com fenolftaleína como indicador.
Para análise dos compostos fenólicos, foram separadas as cascas e sementes de 100 bagas para cada tratamento e repetição. Aproximadamente $0,5 \mathrm{~g}$ de casca triturada em nitrogênio líquido foi homogeneizado em Ultra Turrax (IKA T-18 basic) em solução extratora constituída de metanol acidificado ( $\mathrm{HCl} 1 \%$ ). As antocianinas foram determinadas pelo método de $\mathrm{pH}$ diferencial (Giusti \& Wrolstad, 2000). Os compostos fenólicos totais foram analisados pelo método de Folin-Ciocalteau com base em uma curva padrão de ácido gálico (Amerine \& Ough, 1980; Bergqvist et al., 2001).

As sementes foram imersas em solução alcoólica (metanol-HCl 1\%) em proporção correspondente ao volume de mosto das bagas (González-Neves et al., 2004), e os compostos fenólicos solúveis foram determinados pelo método de Folin-Ciocalteau (Amerine \& Ough, 1980). O teor de potássio foi determinado por fotometria de chama após digestão nítrico-perclórica das bagas (Malavolta et al., 1997).

Os dados das três safras foram submetidos à análise de variância pelo programa SAEG. Foram consideradas como variáveis a média dos parâmetros avaliados nas três safras e os porta-enxertos. A diferença entre as médias foi determinada pelo teste de Tukey, a 5\% de probabilidade.

\section{Resultados e Discussão}

Para as duas cultivares avaliadas, a maior produção foi obtida com a utilização do porta-enxerto 'IAC 572'. Para 'Niágara Rosada', a produtividade obtida com o uso desse porta-enxerto foi de $25,5 \mathrm{Mg} \mathrm{ha}^{-1}$, bastante próxima à de '420 $\mathrm{A}^{\prime}\left(25,4 \mathrm{Mg} \mathrm{ha}^{-1}\right)$, 'RR 101-14' (24,55 $\left.\mathrm{Mg} \mathrm{ha}^{-1}\right)$ e 'Traviú' (23,78 $\left.\mathrm{Mg} \mathrm{ha}^{-1}\right)$. 'IAC 313', '1103 Paulsen' e 'Gravesac' apresentaram produtividade $25 \%$ inferior (em torno de $19 \mathrm{Mg} \mathrm{ha}^{-1}$ ), seguidas por 'IAC 766' e '196-17' (em média 16,15 Mg ha $^{-1}$ ) e pelo pé-franco, cuja produção foi $50 \%$ inferior $\left(12 \mathrm{Mg} \mathrm{ha}^{-1}\right)$ (Figura 1). Para a mesma região deste estudo, Norberto (2006) verificou média de $18 \mathrm{Mg} \mathrm{ha}^{-1}$ para 'Niágara Rosada' enxertada sobre ' 420 A' e conduzida em sistema de espaldeira ao longo de três anos de observação, período no qual, na safra de 2005 , a produtividade observada foi de 25,25 Mg ha-1. Em Taubaté, SP, foram observadas produções médias de 2,69, 2,59 e 1,99 kg por planta em 'Niágara Rosada' com os porta-enxertos 'IAC 313', 'IAC 766' e 'Traviú', respectivamente, no 
sistema de espaldeira (Pauletto et al., 2001b). Entretanto, esses autores não informam a densidade de plantio nem a produtividade por hectare.

A produtividade elevada obtida neste estudo pode ser decorrente da idade do vinhedo e também do excesso de chuvas que incidiu no período de maturação das safras de 2007 e 2008, que influenciou positivamente o peso das bagas. Tal afirmação é corroborada pela comparação dos dados de peso médio dos cachos: 276 g para o porta-enxerto ' $420 \mathrm{~A}$ ', verificados neste trabalho, contra somente $207 \mathrm{~g}$ registrados em 2002 por Orlando (2002) para o mesmo porta-enxerto e na mesma região de estudo.

Em 'Folha de Figo', a produção obtida com o portaenxerto 'IAC 572' foi $30 \%$ superior aos demais portaenxertos mais produtivos ('IAC 766', '1103 Paulsen', 'Traviú', '196-17', 'Gravesac' e 'RR 101-14'). '420 A' apresentou produção $50 \%$ inferior $\left(10,4 \mathrm{Mg} \mathrm{ha}^{-1}\right)$, seguido por 'IAC 313' (7,9 $\left.\mathrm{Mg} \mathrm{ha}^{-1}\right)$ e pelo pé-franco $\left(3,2 \mathrm{Mg} \mathrm{ha}^{-1}\right)$ (Figura 1).

O porta-enxerto 'IAC 313' apresentou alternância de produção entre as safras, com produção estatisticamente semelhante à do pé-franco nas duas cultivares. 'Niágara Rosada' apresentou elevada produção em '420 A', enquanto que, em combinação com 'Folha de Figo', a produção em '420 A' não apresentou diferença estatística em relação ao pé-franco (Figura 1), também devido à alternância de produção entre as safras.

Em comparação com os resultados obtidos por Alvarenga et al. (2002) para a cultivar Niágara Rosada

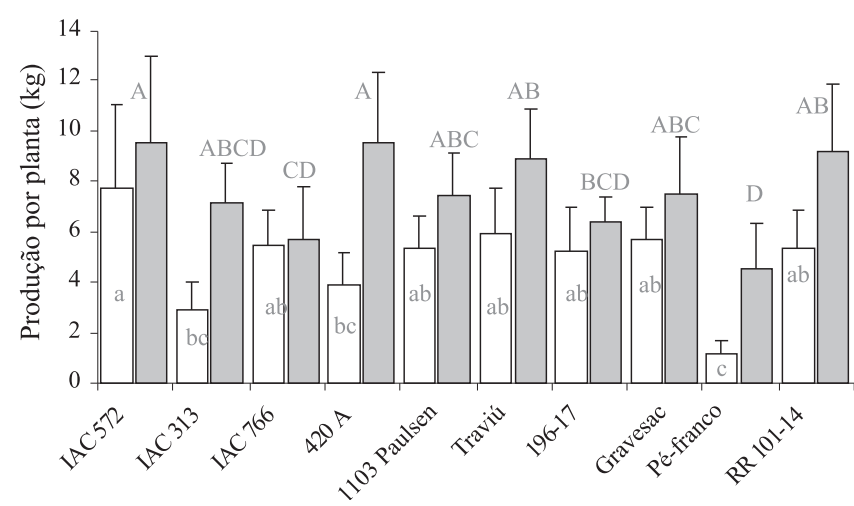

Figura 1. Produção (quilograma por planta) de uva das cultivares Niágara Rosada (ㅁ) e Folha de Figo (ㅁ) relacionada ao porta-enxerto; média das safras 2006-2008. Médias com letras iguais, maiúsculas para Niágara Rosada e minúsculas para Folha de Figo, não diferem entre si pelo teste de Tukey, a $5 \%$ de probabilidade. em início de produção no mesmo campo experimental, verificou-se que 'IAC 572' manteve a característica de conferir maior produção às plantas. Os porta-enxertos '420 A' e 'RR 101-14' aumentaram consideravelmente a produção das videiras com o passar dos anos, enquanto 'IAC 313' e 'IAC 766' apresentaram queda significativa de produção nas plantas mais velhas.

Alvarenga et al. (2002) também observaram, em plantas jovens da cultivar Niágara Rosada, relação positiva entre o vigor vegetativo e a produção. Nas plantas adultas, entretanto, essa relação não foi confirmada em nenhuma das duas cultivares avaliadas (Figura 1, Tabela 1).

Vanden Heuvel et al. (2004) observaram que videiras de 'Chardonnay' e 'Cabernet Franc' enxertadas sobre '5BB' foram mais vigorosas e apresentaram maior produção quando comparadas com as plantas enxertadas sobre 'Riparia'. Entretanto, as bagas provenientes de 'Riparia' apresentaram maior teor de sólidos solúveis. Nuzzo \& Matthews (2006) observaram pouca diferença entre portaenxertos no crescimento das plantas e acúmulo de açúcares nas bagas de videira 'Cabernet Sauvignon'. Entretanto, os porta-enxertos mais vigorosos ('1103 Paulsen' e '140 Ru') produziram bagas com menos cor e maior acidez total.

Por ser uma uva consumida in natura, fatores como o balanço entre açúcares e acidez e a coloração da baga são diferenciais de qualidade para a cultivar Niágara Rosada. Dessa forma, entre os porta-enxertos com melhor produção ('IAC 572', '420 A', 'Traviú', 'RR 101-14', '1103 Paulsen' e 'Gravesac'), aqueles que conferiram as melhores características às bagas foram 'RR 101-14', '420 A' e 'Gravesac'. Destes, 'RR 101-14' e '420 A' destacaram-se pela maior relação sólidos solúveis/acidez, enquanto 'Gravesac' proporcionou maior acúmulo de antocianinas na casca (Tabela 2).

Tabela 1. Massa da poda ( $\mathrm{g}$ ) de inverno de videiras das cultivares Niágara Rosada e Folha de Figo enxertadas sobre diferentes porta-enxertos. Média dos anos 2005 e $2006^{(1)}$.

\begin{tabular}{lcc}
\hline Porta-enxerto & Niágara Rosada & Folha-de-figo \\
\hline 'IAC 572' & $5.810,0 \mathrm{a}$ & $2.956,3 \mathrm{a}$ \\
'IAC 313' & $3.060,0 \mathrm{~cd}$ & $2.442,5 \mathrm{abc}$ \\
'IAC 766' & $3.631,3 \mathrm{bc}$ & $684,2 \mathrm{bc}$ \\
'420 A' & $1.952,5 \mathrm{de}$ & $1.298,8 \mathrm{abc}$ \\
'1103 Paulsen' & $4.250,0 \mathrm{~b}$ & $2.661,3 \mathrm{a}$ \\
'Traviú' & $1.543,8 \mathrm{e}$ & $371,7 \mathrm{c}$ \\
'196-17' & $1.927,5 \mathrm{de}$ & $1.275,0 \mathrm{abc}$ \\
'Gravesac' & $1.525,0 \mathrm{e}$ & $2.001,7 \mathrm{abc}$ \\
'RR 101-14' & $4.492,5 \mathrm{~b}$ & $2.505,0 \mathrm{ab}$ \\
Pé-franco & $2.601,3 \mathrm{cde}$ & $1.351,3 \mathrm{abc}$ \\
\hline${ }^{(1)}$ Médias seguidas de mesma letra, na coluna, não diferem entre si pelo teste
\end{tabular}
de Tukey, a $5 \%$ de probabilidade. 
Para a cultivar Folha de Figo, entre os porta-enxertos mais produtivos ('IAC 572', 'Traviú', 'Gravesac', 'IAC 766', 'RR 101-14', '1103 Paulsen', '196-17'), os que conferiram melhor teor de antocianinas e fenólicos totais foram 'IAC 766', 'Traviú' e '196-17' (Tabela 3). Destes, o que apresentou melhor relação sólidos solúveis/acidez foi o '196-17' (Tabela 4).

$\mathrm{O}$ acúmulo de compostos fenólicos foi maior nas bagas provenientes de plantas com menor vigor vegetativo. 'Niágara Rosada' em 'Gravesac' e 'Folha de Figo' em 'IAC 766', 'Traviú', '196-17' (Tabela 1). Neste caso, fatores como menor competição entre os órgãos vegetativos e produtivos por fotoassimilados ou menor sombreamento dos cachos pelo dossel vegetal menos denso podem ter contribuído para o aumento no teor de antocianinas e compostos fenólicos nas cascas (Jackson \& Lombard, 1993; Bergqvist et al., 2001). Na cultivar Folha de Figo, não foi observada diferença estatística significativa na composição dos compostos fenólicos e antocianinas entre as plantas enxertadas em 'IAC 766', 'Traviú' e '196-17'. Entretanto, as videiras desta cultivar apresentaram vigor bem menor quando comparadas às plantas de 'Niágara Rosada' (Tabela 1).

A diferença de acúmulo de potássio nas bagas foi significativa entre diferentes porta-enxertos. De forma geral, a concentração de potássio variou de 2,0 a 2,4 $\mathrm{g} \mathrm{kg}^{-1}$ de baga na cultivar Folha de Figo, com os maiores teores obtidos nas bagas das plantas enxertadas sobre 'IAC 766', '1103 Paulsen' e 'Gravesac'. 'Niágara Rosada' mostrou-se mais dependente do porta-enxerto na absorção de potássio. Nessa cultivar, a concentração de potássio variou de 1,7 a $2,1 \mathrm{~g} \mathrm{~kg}^{-1}$ de baga, com maior absorção pelas plantas enxertadas em 'IAC 766' e 'Traviú'. Nas duas cultivares, as plantas enxertadas em '196-17' apresentaram menor teor de potássio nas bagas.

O transporte de potássio para as bagas não compete com os açúcares, uma vez que as vias utilizadas são diferentes. O potássio é absorvido pelas raízes e

Tabela 2. Composição físico-química das bagas da cultivar Niágara Rosada sobre diferentes porta-enxertos. Média das safras 2006-2008 ${ }^{(1)}$.

\begin{tabular}{|c|c|c|c|c|c|c|c|}
\hline Porta-enxerto & $\begin{array}{l}\text { Peso da } \\
\text { baga }(\mathrm{g})\end{array}$ & $\mathrm{pH}$ & $\begin{array}{l}\text { Sólidos solúveis } \\
\text { (SS) }\left({ }^{\circ} \text { Brix }\right)\end{array}$ & $\begin{array}{c}\text { Acidez } \\
\left(\text { meq L }^{-1}\right)\end{array}$ & SS/acidez & $\begin{array}{c}\text { Antocianinas } \\
\left(\mathrm{mg} \mathrm{g}^{-1} \text { de casca }\right)\end{array}$ & $\begin{array}{c}\text { Teor de } \mathrm{K} \\
\left(\mathrm{g} \mathrm{kg}^{-1} \text { de baga }\right)\end{array}$ \\
\hline 'IAC 572' & $4,55 \mathrm{~d}$ & $3,16 \mathrm{~d}$ & $14,15 \mathrm{c}$ & $77,80 \mathrm{~b}$ & 0,182 & $0,42 \mathrm{ef}$ & $1,96 a b c$ \\
\hline 'IAC 313' & $4,97 \mathrm{a}$ & $3,18 \mathrm{~d}$ & $14,10 \mathrm{c}$ & $85,78 \mathrm{a}$ & 0,164 & $0,39 \mathrm{f}$ & $2,00 \mathrm{ab}$ \\
\hline 'IAC 766' & $4,19 \mathrm{e}$ & $3,23 \mathrm{c}$ & $15,05 b$ & $85,10 \mathrm{a}$ & 0,177 & $0,50 \mathrm{~cd}$ & $2,09 \mathrm{a}$ \\
\hline '420 A' & $4,56 \mathrm{~cd}$ & $3,25 \mathrm{abc}$ & $15,56 \mathrm{a}$ & $58,31 \mathrm{c}$ & 0,267 & $0,56 \mathrm{~b}$ & $1,73 \mathrm{bc}$ \\
\hline '1103 Paulsen' & $4,82 \mathrm{abc}$ & $3,25 b c$ & $15,53 \mathrm{a}$ & $64,62 \mathrm{c}$ & 0,240 & $0,44 \mathrm{def}$ & $1,87 \mathrm{abc}$ \\
\hline 'Traviú' & $4,67 \mathrm{bcd}$ & $3,25 \mathrm{abc}$ & $15,25 \mathrm{ab}$ & $74,05 b$ & 0,206 & $0,48 \mathrm{cde}$ & $2,13 \mathrm{a}$ \\
\hline '196-17' & $4,70 \mathrm{bcd}$ & $3,29 \mathrm{ab}$ & $15,48 \mathrm{ab}$ & $62,25 \mathrm{c}$ & 0,249 & $0,55 \mathrm{~b}$ & $1,69 \mathrm{c}$ \\
\hline 'Gravesac' & $4,44 \mathrm{de}$ & $3,28 \mathrm{abc}$ & $15,42 \mathrm{ab}$ & $62,79 \mathrm{c}$ & 0,245 & $0,67 \mathrm{a}$ & $1,93 \mathrm{abc}$ \\
\hline 'RR 101-14' & $4,88 \mathrm{ab}$ & $3,27 \mathrm{abc}$ & $15,65 a$ & $57,50 \mathrm{c}$ & 0,272 & $0,51 b c$ & $1,75 \mathrm{bc}$ \\
\hline Pé-franco & $4,63 \mathrm{bcd}$ & $3,30 \mathrm{a}$ & $15,29 \mathrm{ab}$ & $57,92 \mathrm{c}$ & 0,263 & $0,53 b c$ & $1,71 \mathrm{c}$ \\
\hline
\end{tabular}

${ }^{(1)}$ Médias seguidas de mesma letra, na coluna, não diferem entre si pelo teste de Tukey, a 5\% de probabilidade.

Tabela 3. Compostos fenólicos nas cascas e sementes de bagas da cultivar Folha de Figo sobre diferentes porta-enxertos. Média das safras 2006-2008 ${ }^{(1)}$

\begin{tabular}{lccc}
\hline Porta-enxerto & $\begin{array}{c}\text { Antocianinas } \\
\left(\mathrm{mg} \mathrm{g}^{-1} \text { de casca }\right)\end{array}$ & $\begin{array}{c}\text { Fenólicos totais } \\
\left(\mathrm{mg} \mathrm{g}^{-1} \mathrm{de} \mathrm{casca}\right)\end{array}$ & $\begin{array}{c}\text { Fenólicos totais } \\
\left(\mathrm{mg} \mathrm{g}^{-1} \text { de semente }\right)\end{array}$ \\
\hline 'IAC 572' & $8,38 \mathrm{c}$ & $10,39 \mathrm{~d}$ & $44,43 \mathrm{bc}$ \\
'IAC 313' & $8,40 \mathrm{c}$ & $11,04 \mathrm{bcd}$ & $46,02 \mathrm{ab}$ \\
'IAC 766' & $9,86 \mathrm{a}$ & $11,65 \mathrm{abc}$ & $50,21 \mathrm{a}$ \\
'420 A' & $8,24 \mathrm{c}$ & $10,75 \mathrm{bcd}$ & $37,94 \mathrm{e}$ \\
'1103 Paulsen' & $8,96 \mathrm{bc}$ & $11,88 \mathrm{ab}$ & $39,12 \mathrm{cde}$ \\
'Traviú' & $10,47 \mathrm{a}$ & $12,58 \mathrm{a}$ & $45,11 \mathrm{ab}$ \\
'196-17' & $10,47 \mathrm{a}$ & $12,50 \mathrm{a}$ & $38,39 \mathrm{de}$ \\
'Gravesac' & $8,95 \mathrm{bc}$ & $11,66 \mathrm{abc}$ & $44,58 \mathrm{bc}$ \\
'RR 101-14' & $8,53 \mathrm{c}$ & $10,59 \mathrm{~cd}$ & $41,99 \mathrm{bcde}$ \\
Pé-franco & $9,68 \mathrm{ab}$ & $11,85 \mathrm{ab}$ & $43,42 \mathrm{bcd}$ \\
\hline
\end{tabular}

${ }^{(1)}$ Médias seguidas de letras iguais, na coluna, não diferem entre si pelo teste de Tukey, a 5\% de probabilidade.
Tabela 4. Composição físico-química das bagas da cultivar Folha de Figo sobre diferentes porta-enxertos. Média das safras 2006-2008 ${ }^{(1)}$.

\begin{tabular}{llllccc}
\hline Porta-enxerto & $\begin{array}{c}\text { Peso da } \\
\text { baga }(\mathrm{g})\end{array}$ & \multicolumn{2}{c}{$\mathrm{pH}$} & $\begin{array}{r}\text { Sólidos sol. } \\
(\mathrm{SS})\left({ }^{\circ} \mathrm{Brix}\right)\end{array}$ & $\begin{array}{r}\text { Acidez } \\
\left(\mathrm{meq} \mathrm{L}{ }^{-1}\right)\end{array}$ & $\begin{array}{r}\text { SS/acidez } \\
\left(\mathrm{g} \mathrm{kg}^{-1} \text { por baga }\right)\end{array}$ \\
\hline 'IAC 572' & $2,47 \mathrm{ab}$ & $3,15 \mathrm{c}$ & $13,10 \mathrm{c}$ & $91,60 \mathrm{ab}$ & 0,143 & $2,21 \mathrm{ab}$ \\
'IAC 313' & $2,50 \mathrm{ab}$ & $3,20 \mathrm{abc}$ & $13,43 \mathrm{bc}$ & $84,68 \mathrm{bc}$ & 0,158 & $2,02 \mathrm{~b}$ \\
'IAC 766' & $2,58 \mathrm{a}$ & $3,20 \mathrm{abc}$ & $14,06 \mathrm{ab}$ & $101,00 \mathrm{a}$ & 0,139 & $2,35 \mathrm{a}$ \\
'420 A' & $2,45 \mathrm{ab}$ & $3,19 \mathrm{bc}$ & $14,27 \mathrm{ab}$ & $67,89 \mathrm{~d}$ & 0,210 & $2,18 \mathrm{ab}$ \\
'1103 Paulsen' & $2,52 \mathrm{a}$ & $3,20 \mathrm{abc}$ & $14,35 \mathrm{ab}$ & $91,28 \mathrm{ab}$ & 0,157 & $2,39 \mathrm{a}$ \\
'Traviú' & $2,47 \mathrm{ab}$ & $3,21 \mathrm{ab}$ & $14,35 \mathrm{ab}$ & $96,18 \mathrm{ab}$ & 0,149 & $2,18 \mathrm{ab}$ \\
'196 -17' & $2,47 \mathrm{ab}$ & $3,23 \mathrm{ab}$ & $14,43 \mathrm{a}$ & $76,83 \mathrm{~cd}$ & 0,188 & $1,98 \mathrm{~b}$ \\
'Gravesac' & $2,47 \mathrm{ab}$ & $3,25 \mathrm{a}$ & $14,72 \mathrm{a}$ & $86,26 \mathrm{bc}$ & 0,170 & $2,35 \mathrm{a}$ \\
'RR 101-14' & $2,44 \mathrm{ab}$ & $3,23 \mathrm{ab}$ & $14,71 \mathrm{a}$ & $75,74 \mathrm{~cd}$ & 0,194 & $2,26 \mathrm{ab}$ \\
Pé-franco & $2,34 \mathrm{~b}$ & $3,15 \mathrm{c}$ & $14,36 \mathrm{ab}$ & $86,99 \mathrm{abc}$ & 0,165 & $2,07 \mathrm{ab}$ \\
\hline
\end{tabular}

${ }^{(1)}$ Médias seguidas de letras iguais, na coluna, não diferem entre si pelo teste de Tukey, a $5 \%$ de probabilidade. 
distribuído para todas as partes da planta. No início do desenvolvimento vegetativo, grande parte do potássio absorvido é concentrada nas folhas. Após a mudança de cor das bagas, um rápido aumento no conteúdo de potássio é observado como resultado da redistribuição do elemento das folhas para as bagas (Conde et al., 2007).

Main et al. (2002) também não observaram relação entre produção e conteúdo de potássio no mosto de uvas 'Chardonel' cultivadas em Arkansas (EUA). As videiras enxertadas sobre 'Cynthiana' e '110 R' apresentaram menor $\mathrm{pH}$ e menores concentrações de potássio nas mesmas condições de sólidos solúveis e acidez em relação às uvas provenientes de pé-franco, 'Freedom' e '5BB'.

\section{Conclusões}

1. O porta-enxerto 'IAC 572' induz maior vigor e produção das cultivares de uva Niágara Rosada e Folha de Figo.

2. Porta-enxertos de menor vigor induzem maior acúmulo de antocianinas e compostos fenólicos nas cascas.

3. O porta-enxerto 'Gravesac' proporciona produção e bagas com teor de sólidos solúveis, acidez e teor de antocianinas superiores aos demais porta-enxertos na cultivar Niágara Rosada.

4. Os porta-enxertos 'Traviú' e '196-17' testados na cultivar Folha de Figo favorecem maiores teores de antocianinas e sólidos solúveis totais.

5. Uvas da cultivar Folha de Figo enxertadas em '196-17' apresentam menor acidez.

6. A cultivar Niágara Rosada é mais dependente do porta-enxerto na absorção de potássio que a cultivar Folha de Figo.

\section{Agradecimentos}

ÀFundaçãodeAmparoà PesquisadoEstadodeMinas Gerais e ao Conselho Nacional de Desenvolvimento Científico e Tecnológico, pelo auxílio financeiro e concessão de bolsas; ao Dr. Marcos Roberto Lopes do Nascimento, por ceder as instalações da Comissão Nacional de Energia Nuclear de Poços de Caldas, MG, para a realização da digestão nítrico-perclórica das bagas.

\section{Referências}

ALVARENGA, A.A.; REGINA, M. de A.; FRÁGUAS, J.C.; CHALFUN, N.N.J.; SILVA, A.L. da. Influência do porta-enxerto sobre o crescimento e produção da cultivar de videira Niágara Rosada (Vitis labrusca L. x Vitis vinifera L.), em condições de solo ácido. Ciência e Agrotecnologia, v.26, p.1459-1464, 2002.

AMERINE, M.A.; OUGH, C.S. Methods for analysis of musts and wines. New York: Willey, 1980. 341p.

AUGUSTIN, M.; GLORIES, Y. Maturite phenolic dês raisins rouges: application au millesime 1991. In: UNIVERSITÉ DE BORDEAUX. Rapport des activités de recherches 1990-1992. Bordeaux: Université de Bordeaux, 1992. p.55-57.

BERGQVIST, J.; DOKOOZLIAN, N.; EBISUDA, N. Sunlight exposure and temperature effects on berry growth and composition of Cabernet Sauvignon and Grenache in the central San Joaquin Valley of California. American Journal of Enology and Viticulture, v.52, p.1-7, 2001.

CONDE, C.; SILVA, P.; FONTES, N.; DIAS, A.C.P.; TAVARES, R.M.; SOUSA, M.J.; AGASSE, A.; DELROT, S.; GERÓS, H. Biochemical changes throughout grape berry development and fruit and wine quality. Food, v.1, p.1-22, 2007.

EZZAHOUANI, A.; WILLIAMS, L.E. The influence of rootstock on leaf water potencial, yield and berry composition of Ruby Seedless grapevines. American Journal of Enology and Viticulture, v.46, p.559-563, 1995.

GIL, G.F.; PSZCZÓLKOWSKI, P. Viticultura: fundamentos para optimizar producción y calidad. Chile: Ediciones Universidad Católica de Chile, 2007. 535p.

GIUSTI, M.M.; WROLSTAD, R.E. Characterization and measurement of anthocyanins by UV-visible spectroscopy. In: WROLSTAD, R.E. (Ed.). Current protocols in food analytical chemistry. New York: Willey, 2000.

GONZÁLEZ-NEVES, G.; CHARAMELO, D.; BALADO, J.; BARREIRO, L.; BOCHICCHIO, R.; GATTO, G.; GIL, G.; TESSORE, A.; CARBONNEAU, A.; MOUTOUNET, M. Phenolic potencial of Tannat, Cabernet Sauvignon and Merlot grapes and their correspondence with wine composition. Analytica Chimica Acta, v.513, p.191-196, 2004.

GUERRA, C.C. Maturação da uva e condução da vinificação para a elaboração de vinhos finos. In: SIMPÓSIO MINEIRO DE VITICULTURA E ENOLOGIA, 1., 2002, Andradas. Viticultura e enologia: atualizando conceitos. Caldas: Epamig, 2002. p.179-192.

JACKSON, D.I.; LOMBARD, P.B. Environmental and management practices affecting grape composition and wine quality: a review. American Journal of Enology and Viticulture, v.44, p.409-430, 1993.

MAIN, G.; MORRIS, J.; STRIEGLER, K. Rootstock effects on Chardonel productivity, fruit and wine composition. American Journal of Enology and Viticulture, v.53, p.37-40, 2002.

MALAVOLTA, E.; VITTI, G.C.; OLIVEIRA, S.A. Metodologia para análise de elementos em material vegetal. In: MALAVOLTA, E.; VITTI, G.C.; OLIVEIRA, S.A. Avaliação do estado 
nutricional das plantas: princípios e aplicações. 2.ed. Piracicaba: Potafos, 1997. cap.6, p.231-307.

NORBERTO, P.M. Sistemas de condução em videira: análises agronômica e ecofisiológica. 2006. 118p. Tese (Doutorado) Universidade Federal de Lavras, Lavras.

NUZZO, V.; MATTHEWS, M.A. Response of fruit growth and ripening to crop level in dry-farmed Cabernet Sauvignon on four rootstocks. American Journal of Enology and Viticulture, v.57, p.314-324, 2006.

ORLANDO, T.G.S. Características ecofisiológicas de cultivares de videira em diferentes sistemas de condução. 2002. 126p. Tese (Doutorado) - Universidade Federal de Lavras, Lavras.

PAUlETTO, D.; MOURÃO FILHO, F. de A.A.; KLUGE, R.A.; SCARPARE FILHO, J.A. Efeito do porta-enxerto na qualidade do cacho da videira 'Niágara Rosada'. Pesquisa Agropecuária Brasileira, v.36, p.935-939, 2001a.

PAULETTO, D.; MOURÃO FILHO, F. de A.A.; KLUGE, R.A.; SCARPARE FILHO, J.A. Produção e vigor da videira 'Niágara Rosada' relacionados com o porta-enxerto. Pesquisa Agropecuária Brasileira, v.36, p.115-121, 2001b.

PROTAS, J.F. da S.; CAMARGO, U.A.; MELLO, L.M.R. Vitivinicultura brasileira: regiões tradicionais e pólos emergentes. Informe Agropecuário, v.27, p.7-15, 2006.

REGINA, M. de A.; ALVARENGA, A.A.; CHALFUN, N.N.J.; CHALFUN JÚNIOR, A. Levantamento nutricional e diagnóstico agronômico dos vinhedos de Caldas. Revista Brasileira de Fruticultura, v.20, p.15-20, 1998.

RIBEIRO, A.C.; GUIMARÃES, P.T.G.; ALVAREZ VENEGAS, V.H. (Ed.). Recomendação para o uso de corretivos e fertilizantes em Minas Gerais: 5a aproximação. Viçosa: Comissão de Fertilidade do Solo do Estado de Minas Gerais, 1999. 359p.

RIZZON, L.A.; SGANZERLA, V.M.A. Ácidos tartárico e málico no mosto de uva em Bento Gonçalves-RS. Ciência Rural, v.37, p.911-914, 2007.

TECCHIO, M.A.; PAIOLI-PIRES, E.J.; TERRA, M.M.; TEIXEIRA, L.A.J.; LEONEL, S. Características físicas e acúmulo de nutrientes pelos cachos de 'Niágara Rosada' em vinhedos na região de Jundiaí. Revista Brasileira de Fruticultura, v.29, p.621-625, 2007.

TERRA, M.M.; PIRES, E.J.P.; POMMER, C.V.; BOTELHO, R.V. Produtividade da cultivar de uva de mesa Niágara Rosada sobre diferentes porta-enxertos, em Monte Alegre do Sul-SP. Revista Brasileira de Fruticultura, v.25, p.549-551, 2003.

VANDEN HEUVEL, J.E.; PROCTOR, J.T.A.; SULLIVAN, J.A.; FISHER, K.H. Influence of training/trellising system and rootstock selection on productivity and fruit composition of Chardonnay and Cabernet Franc grapevines in Ontario, Canada. American Journal of Enology and Viticulture, v.55, p.253-264, 2004.

Recebido em 13 de fevereiro de 2009 e aprovado em 15 de maio de 2009 